\title{
Why do Scandinavians Work?
}

\author{
Torben M. Andersen
}

\section{CESIFO WORKING PAPER No. 3068 \\ CATEGORY 4: LABOUR MARKETS \\ MAY 2010}
An electronic version of the paper may be downloaded
- from the SSRN website:
www.SSRN.com
- from the RePEc website:
- from the CESifo website:
www.RePEc.org
www.CESifo-group.org/wp




\title{
Why do Scandinavians Work?
}

\begin{abstract}
Recent debates have suggested that taxation is very detrimental to labour force participation and employment. However, some countries - notably the Scandinavian - stand out as contradictions to this view since they have managed to sustain high labour force participation rate despite high tax rates and a generous social safety net. This either refutes the standard incentive argument or leave the Scandinavian countries as a puzzle. This paper argues that both the standard view and the Scandinavian experience can be reconciled when taking into account both the pecuniary and non-pecuniary incentives build into the social safety net. The social safety net in the Scandinavian countries is at the same time both generous and employment conditioned. It is shown that these conditionalities can make high labour force participation consistent with a high marginal effective taxation of labour, and that it on the margin lowers the marginal costs of public funds. Such employment conditionalities make it possible to achieve distributional objectives without jeopardizing the incentive structure.
\end{abstract}

JEL-Code: J01.

Keywords: tax incentives, labour supply, activation.

Torben M. Andersen

School of Economics and Management

Aarhus University

Denmark

tandersen@econ.au.dk

May 2010

Comments and suggestions by Alfonso Arpia and Stephan Hupfeld and participants at a DG ECFIN seminar, the CESifo conference "Reform of the Welfare State: A New European Model" and the Society of Economic Dynamics conference in Istanbul are gratefully acknowledged. 


\section{Introduction}

Scandinavian countries are characterized by both high labour force participation and employment rates as well as a high tax burden on labour income and a generous social safety net. This challenges the standard perception that both taxes and transfers reduce incentives to work.

The role of taxes for economic performance in general and labour market participation and employment in particular is a recurrent theme. A recent wave in this debate has been fuelled by the controversial paper by Prescott (2004), arguing that differences in labour supply (measured as total hours supplied relative to population size) between the US and some larger European countries can be accounted for by the difference in tax rates. Hence, by implication, if these European countries were to reduce taxes to the US level, the labour input would be about the same on a per capita basis, and such reductions would be self-financing (see also Ohanion, Raffo and Rogerson (2006)).

While provocative, these claims are based on an implausibly large labour supply elasticity way above any available empirical micro evidence ${ }^{12}$. Moreover, a closer look at the cross-country evidence reveals a more complicated picture than implied by the simple "tax and labour supply" view, and the performance of the Scandinavian countries in particular is an outlier or paradox in this respect.

The co-existence of a high tax burden on labour and a generous safety net in the Scandinavian countries seem to pose a significant distortion of labour supply incentives. In the economics literature, a generous social safety net is often portrayed as a "subsidy to leisure" or as "paying people for not working".

Many government spending programs implicitly provide a marginal subsidy to leisure since they stipulate that benefits are conditional on not working, or that the benefit is reduced in response to any labour income. Relevant examples include some components of social security, unemployment insurance, traditional welfare programs and disability (Rogerson, 2007, p 73).

This line of reasoning identifies the composite tax rates (metr: marginal effective tax rates) on labour market participation (i.e. the combined effect of taxes lowering the return to work, and the loss of transfers) as crucial for determining labour force participation, and by implication they are high in countries like the Scandinavian with a generous tax financed social safety net.

In the political science literature, the same issue appears but from a different angle since the focus is on the extent to which social policies lead to a decommodification of labour. By decommodification is understood that selling of labour ${ }^{3}$ is not a necessity to maintain a decent standard of living.

\footnotetext{
${ }^{1}$ Prescott (2004) assumes a labour supply elasticity of nearly 3. This is significantly larger than in micro studies which usually find the elasticities to be small and below one. For recent surveys see e.g. Evers, De Moij and van Vuuren (2005) and Meghir and Phillips (2008). Recent work has assessed elasticities using reported income which leads to higher elasticities (although the interpretation is open to debate, see Chetty (2008)), but even these elasticities are not as high as assumed by Prescott,

${ }^{2}$ Other arguments have been that Europeans have a stronger preference for leisure, that the welfare state via generous benefit levels lowers labour supply, and the role of imperfect competition (unions), see e.g. Alesina, Glaeser and Sacerdote (2005), Ljundqvist and Sargent (2007), and Gordon (2006).

${ }^{3}$ Also expressed as "the concept refers to the degree to which individuals, or families, can uphold a socially acceptable standard of living independently of market participation" Esping-Andersen (1990, p 37).
} 
A minimal definition must entail that citizens can freely, and without potential loss of job, income, or general welfare, opt out of work when they themselves consider it necessary (Esping-Andersen, 1990, p 23).

Decommodification is seen as an integral part of the universal welfare model stressing that entitlements are based on citizenship and needs rather than performance. If the social safety net in the Scandinavian countries is taken to support decommodification of labour (see Esping-Andersen (1990)), it follows that the Scandinavian countries come close to the universal model ${ }^{4}$. The decommodification interpretation goes hand in hand with the incentive view of the welfare state; that is, the economic incentives to supply labour are weakened by welfare arrangements.

This paper argues that neither of the above views give an accurate description of the Scandinavian welfare model, and that conditionalities in the social safety net help explain the employment-tax/social safety net pattern observed. The social safety net is generous by international standards in the Scandinavian countries, and it builds on universal individual rights which are collectively financed by taxation. However, the scheme is at the same time conditional on individual behaviours. These conditions have a strong employment or work focus, that is, the eligibility not only for unemployment insurance both also social assistance is conditional on documented active job search, participation in activation programmes (job training, education etc.) etc. Hence, by focussing only on the pecuniary aspects of the system one may wrongly conclude that the system subsidies non-work, but by including the conditionalities or nonpecuniary incentives it follows that generous benefits can be consistent with maintaining incentives for job search and work. This can also be phrased in the way that these conditionalities make it possible to offer more generous transfers consistent with distributional objectives without jeopadizing the incentive structure for work. This interpretation has implications not only in accounting for the experience of the Scandinavian countries but also for the more general debate about the role of incentives and design of labour market and social policies.

There is a vast literature exploring the incentive implications of taxes and the social safety net. In relation to the specific theme of this paper it is most relevant to point to other explanations why a generous social safety net is not "over exploited". One key argument is stigmatization arising when individuals find that living on transfers is less socially acceptable than living on earned income. In a seminal paper Moffitt (1983) shows how stigmatization can explain why take up rates among those eligible for specific social transfer programmes are less than $100 \%$. While stigmatization is surely an important aspect it is not an obvious explanation of the Scandinavian experience. Rather it has been a policy aim to minimize stigmatization by making eligibility to various welfare arrangements rightsbased. The basic argument is that it from a welfare perspective is not desirable that take up rates are below 100\% since this implies that some deserving abstains from receiving the aid they are intended to get, and for those who claim the transfer there is no point in lowering their well-being by making them perceive to be outsiders. The aim of the Scandinavian model is to foster social inclusion and avoid

\footnotetext{
${ }^{4}$ Various proposals on classification of welfare regimes or models have been made in the literature. Esping-Andersen (1990) made seminal a distinction between the liberal/residual, the continental/corporatist and the universal/social democratic/Scandinavian welfare model. This is used here since it is a convenient way by which to focus on the division of labour between the market, the civil society and the state. However, no country fits perfectly into these model categories, and countries with strong universal elements are also found outside Scandinavia, e.g. the Netherlands.
} 
stigmatization. Another important aspect is the role of norms and the Scandinavian countries are often portrayed as having a strong work ethic and strong work norms. Clearly strong norms can counteract economic incentives (see e.g. Lindbeck et.al. (1999, 2003), Algan and Cahuc (2009)) and help explain why employment is high despite weak direct economic incentives for labour supply. However, sustaining strong work norms if they are inconsistent with economic incentives create a very liable situation in contrast to the very resilient position of the Scandinavian position. Policies may both strenghen norms and also be supported by norms. The employment conditionalities in the social safety net perform this dual role since they maintain the focus on employment and thereby contribute to support work norms. Moreover, if there are strong work norms it is easier to obtain political support for attaching work or employment conditionalities to the social safety net, since the working population (and thus the majority of tax payers) find that transfer recipients like the working population have to offer something in return for their income (desert sensitive political preferences).

Based on an account of the design of the social safety net in the Scandinavian countries this paper develops a simple model accounting for both the pecuniary (taxes and benefits) and non-pecuniary (employment conditionalities) incentives to work, and show how the latter helps account for high labour force participation and employment rates despite high taxes and a generous social safety net. This can also be phrased in the way that the employment conditionalities work to lower the distortionary effects of taxation. It is furthermore shown that such employment conditionalities make it possible for policy makers with strong distributional goals to shift the trade-off between efficiency and equity concerns. This paper is closely related to a mainly empirical literature exploring the effects of active labour market policies (for surveys see e.g. Kluver(2006)) for labour supply and employment. In general such policies may affect employment possibilities via human capital effects and search effects, but the present paper focus for simplicity entirely on the incentive effects of such policies ${ }^{5}$. The paper is also closely related to work on labour supply on the extensive margin (for surveys see e.g. Evers et. al (2005) and Meghir and Phillips (2008))

The paper is organized as follows: Section 2 gives in a very brief form an account of the Scandinavian position in comparative perspective, and outlines the conditionalities built into the social safety net. It is shown that when accounting for both pecuniary and non-pecuniary incentives the Scandinavian position no longer remains a puzzle. Section 3 develops a simple model of labour supply, focussing on the interplay between pecuniary and non-pecuniary incentives to show how the latter in a fundamental way changes the incentive structure and thus the distortions arising from a policy framework like the one adopted in Scandinavia. This section considers also briefly the welfare rationale for employment conditionalities in the social safety net, and section 4 offers a few concluding remarks.

\footnotetext{
${ }^{5}$ The theoretical literature on active labour market policies has mainly focused on wage effects, but more recently the search effects have also been explored (see Holzner, Meier and Werding(2006) and Andersen and Svarer (2008). Besley and Coate (1992) addressed in a seminal paper workfare as part of a poverty alleviation scheme. The model assumed a given budget for transfers and assumed that transfers where given as a supplement to private market income (endogenous working hours). The focus was on screening between deserving and non-deserving under incomplete information.
} 


\section{Scandinavia - an outlier?}

The conventional metric to measure the extent to which work incentives are distorted by taxes and the social safety net is the so-called marginal effective tax rate (metr). The metr includes both the taxation of income earned when working and the loss of transfer when shifting from non-work to work. This double effect implies that the metr can be rather high, both in general in countries with a generous tax financed social safety net (see European Commission (2005) and Centeno (2005)), and for specific groups where it can be close to or even above $100 \%{ }^{6}$. Figure 1 shows that the metr is $90-85 \%$ in Denmark and Sweden suggesting very weak work incentives in the two countries.

Figure 1: Marginal effective rate of taxation when shifting from non-work to work (metr)

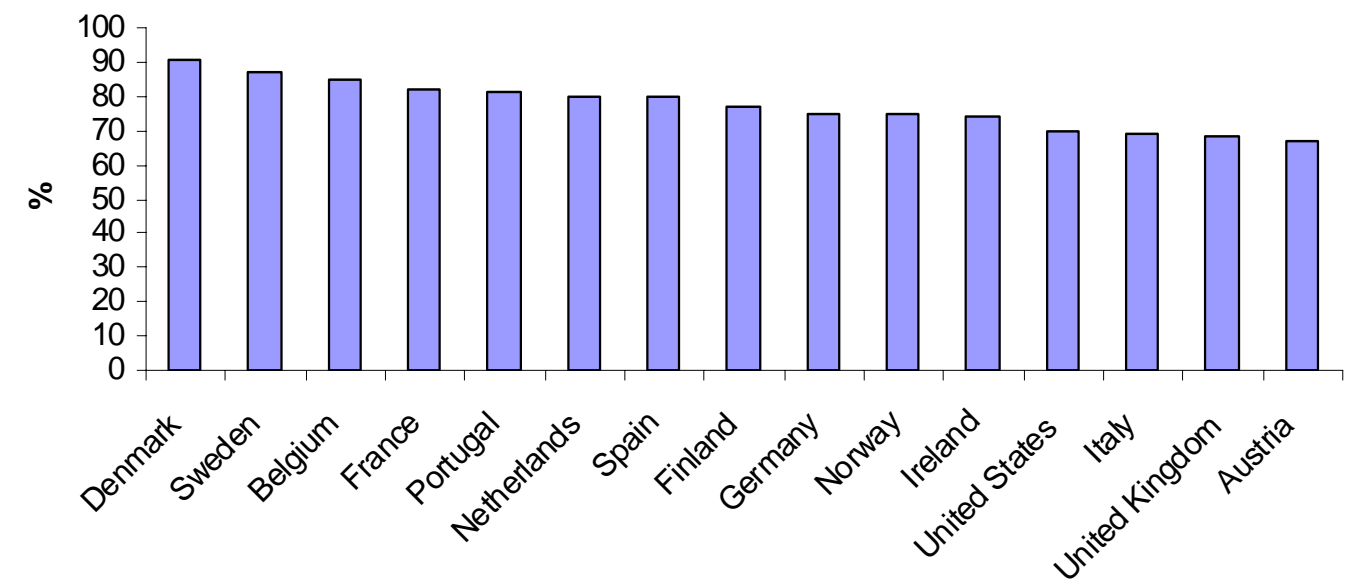

Note: Data applies to 2004

Source: Eurostat

It is well-known that labour force participation and employment rates in the Scandinavian countries are high by international standards and close to the US level often used as a benchmark case. The high level applies both for men and women, and also to groups with low education which may be particularly affected by the high metr, (see e.g. Andersen (2009) for data and references). Figure 2 provides a cross plot of the labour force participation rate and the metr for European countries. This figures thus not yield direct support to the mainstream view that a high metr is detrimental to labour supply and thus employment, if anything it displays a (weak) positive correlation between labour force participation rates and the metr. This "wrong" correlation is mainly driven by the Scandinavian outliers (DK, N, and S are indicated by circles in the figure) having much higher employment rates than to be expected given the high levels of the metr (see below). Is Scandinavia a strange outlier or can the Scandinavian experience be reconciled with standard views on the role of incentives?

\footnotetext{
${ }^{6}$ One striking finding is that some persons are in employment even though they get a very low or even negative economic return from working (see also e.g. Pedersen and Smith (2002)).
} 
Figure 2: Labour force participation and the marginal effective taxation rate on work

\section{European countries}

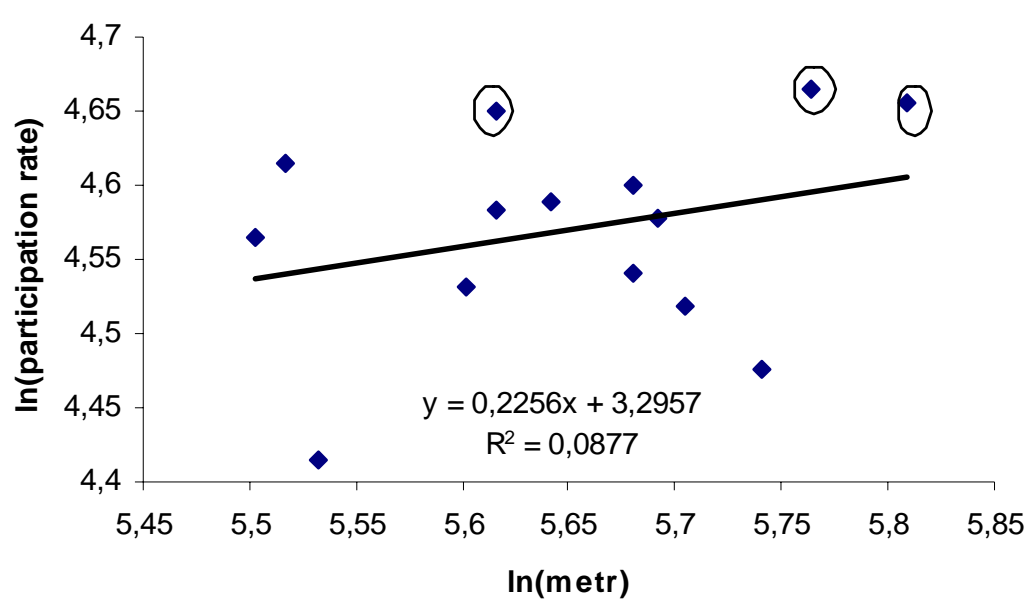

Note: The participation rate is for the age group 15-64, and the metr is the marginal effective tax rate from shifting between non-work and work, taking into account taxes and transfer income. Data: See tabel 1.

\subsection{The social safety net and employment conditionalities}

Assessing work incentives solely from the metr is too simple and presumes that the option of living on transfers is available without any constraints or conditions. This easily leads to conclusions like "subsidizing leisure" or "paying people for not working". However, this is an empirically inaccurate characterization of the welfare policies underlying the Scandinavian model since they do not in general leave various benefits as a free choice but include a number of conditionalities determining eligibility.

By conditionalities are understood the conditions under which the individual acquires access to tax financed transfers and services. A basic question is whether the entitlement is a citizen's right, or whether it depends on some prior action like payment of a contribution, membership fee and the like. A universal welfare arrangement is defined as one where the "entry" condition is a citizen's right granted at an individual level. However, if citizenship was the only condition, social transfers would amount to an unconditional income, i.e. a so-called demo-grant or basic income ${ }^{7}$. The transfers are however not unconditional, and the conditionalities basically serve the purpose of ensuring targeting and maintaining work incentives.

Labour market and social policies in the Scandinavian countries have a long tradition for building on a so-called "work-line" based on rights and duties. Individuals have social rights but also duties with respect to actions to be taken. The Swedish Rehn-Maidner model is a classical reference for pointing to the duality between a generous social safety net and a compressed wage structure on the one hand and active labour market policies on the other (see e.g. Erixon (2008)). Active labour market policies should

\footnotetext{
${ }^{7} \mathrm{~A}$ basic income is sometimes argued as being the ultimate example of decommodification of labour and completion of social rights, cf. Marshall (1950).
} 
be understood broadly to include various requirements attached to the eligibility in the social safety net going from active job search to participation in education programmes, or job training. These policies as such are not specific to the Scandinavian countries, but they stand out in the clustering of policies as reflected by the fact that the Scandinavian countries top the list for both transfer generosity and spending on active labour market policies (see OECD (2009)).

As an illustration of the complementarity between rights and duties in the design of the social safety net figure 3 illustrates some key elements of the danish system. The systems in Norway and Sweden are alike, but the danish is the most generous in terms of replacement rate and duration for unemployment benefits. The figure shows in the upper part the level of compensation offered depending on the duration of a non-work spell for a person who initially is eligible for unemployment benefits ${ }^{8}$ and later transits into social assistance. The benefit level can not exceed $90 \%$ of the previous wage or a cap (indexed to the general wage development), and therefore the replacement rate is declining in the previous wage income. Accordinly low income groups have a replacement rate of $90 \%$ while the average production worker has a replacement rate of about $65 \%$. The duration of unemployment benefits is four years after which the unemployed transit into the social assistance system offering a lower (means tested) benefit. In terms of benefit levels and duration the scheme is rather generous by international standards. The other but equally important side of the scheme is the various requirements - employment conditionalities - attached to claiming of transfers illustrated in the lower part of figure 3. During a benefit spell the requirements are stepped up from an initial requirement of active job search to full time activation. Upon transition to social assistance there are similar requirements for people assessed capable of working. These requirements underlines that receiving transfers is not a free choice as an alternative to work.

Figure 3: The Danish social safety net in case of unemployment

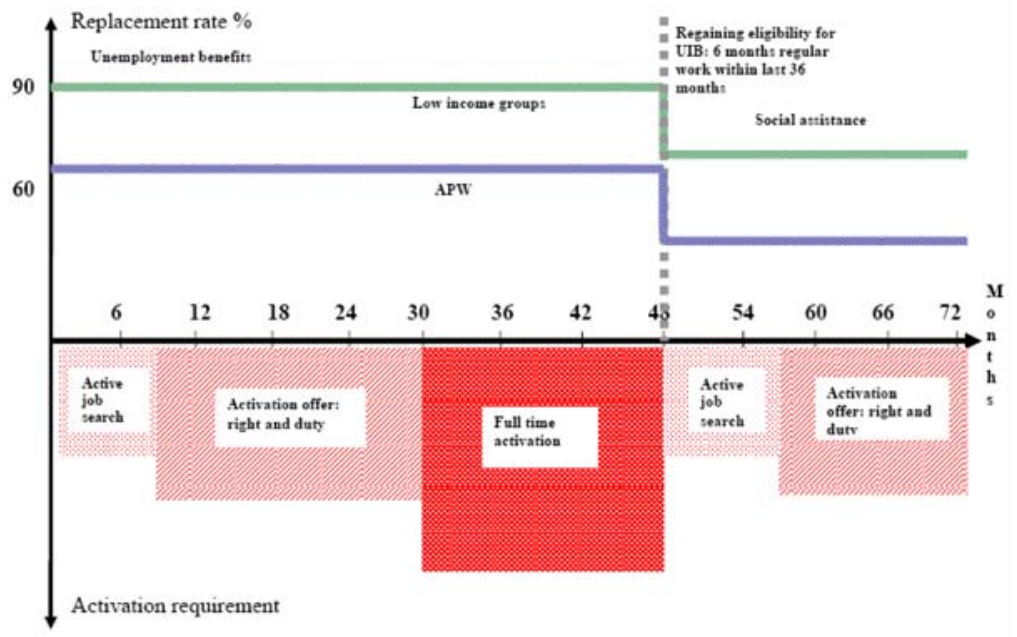

Note: Diagram drawn for an individual fulfilling the requirements for unemployment at the moment of becoming unemployed. Social assistance is calculated on the basis of benefits for a single person. The activation requirements are for those above the age of 30 . More strict conditions apply for individuals below 30 . APW refers to the replacement rate for an average production worker. The replacement rate is lower because the system has an absolute cap.

\footnotetext{
${ }^{8}$ Unemployment insurance is voluntary in Denmark and Sweden, but tax subsidized. Norway has a compulsory unemployment insurance scheme.
} 
The system thus has a dual structure with respect to incentives via both generous benefits (levels and duration) and employment conditionalities. This policy package has the main purpose of changing the efficiency-equity trade-off in the direction of making is possible to pursue ambitious distributional goals without jeopardizing the incentive structure too $\mathrm{much}^{9}$.

\subsection{Explaining the puzzle?}

As illustrated in figure 2 the Scandinavian countries are a puzzle relative to the standard views on the role of taxes and the social safety net for incentives. If anything this evidence seems to refute the standard view. However, the puzzle may be explained by taking into account the employment conditionalities of welfare arrangements, cf table 1 . The table shows the results of the following simple empirical exercise relating the labour force participation rate to the marginal effective tax rate (metr), and two measures affecting the marginal value of non-working time for individuals namely publicly provided services in kind (services) and expenses on active labour market policies (almp). Data is for 14 Western European countries (EU15 minus Luxembourg and Greece and plus Norway) and applies to 2005. Data is measured relative to the $\mathrm{US}^{10}$.

There are numerous measurement problems involved in assessing the role of pecuniary and nonpecuniary incentives for labour force participation/employment. First, the participation constraint is most binding for individuals with low potential market income, and hence by using aggregate labour force participation, the role of incentives may be underestimated. However, there is no readily available measure of labour supply for the potential low income group. Second, the role of conditionalities in welfare policies is very difficult to measure, and the expenditure levels are very poor indicators of the whole complex of rules and regulations pertaining to receiving welfare benefits.

Despite these reservations the results of the simple regressions reveal some interesting findings ${ }^{11} 12$. First, the regressions are significantly improved by the inclusion of the two measures related to the employment focus of welfare policies, and the a priori expected signs are found to the employment supportive variables. The first column corresponds to figure 2 and displays a very poor fit and a wrongly signed effect of the metr. When controlling for the employment conditionalities (services and almp) the fit improves significantly and the variables get the expected signs (also the metr variable) showing that incentives are affected negatively by the metr and positively by the employment conditionalities, and this resolves the puzzle displayed in figure 2. The table also reports the regressions for men and women separately, and the same qualitative findings appear, although as expected, the effects are much smaller

\footnotetext{
${ }^{9}$ Conditionalities also serve the purpose of screening between the "deserving" and "non-deserving" , so-called targeting or tagging, cf. Akerlof (1978). See also Nichols and Zeckhauser (1982). This screening may either arise via a gate-keeper checking whether given eligibility conditions are met, or via self-selection, cf Besley and Coate $(1992,1995)$.

${ }^{10}$ The results are almost the same if variables are not measured relative to US values.

${ }^{11}$ The estimation is presented here for labour force participation rather than employment since the latter involves demand aspects. However, labour supply numbers may be boosted if agents not actively searching for jobs are included. Hence, more explicit employment conditionalities may reduce registered labour supply. The estimation has also been made with the employment rate (age group 15-64) as the dependent variable, with the same results.

${ }^{12}$ It is particularly noteworthy that the introduction of the two control variables implies a significant improvement of the explanatory power of the model (compare also figure 1), even though it remains parsimonious.
} 
for males than females, and in particular services in-kind have a significant positive effect on labour force participation for females.

Table 1: Estimated labour force participation equation

\begin{tabular}{ccccccc}
\hline \hline & \multicolumn{2}{c}{ Total } & \multicolumn{2}{c}{ Males } & \multicolumn{2}{c}{ Females } \\
\hline constant & 3.30 & 5.23 & 4.40 & 5.22 & 1.96 & 5.22 \\
& $(2.78)$ & $(3.95)$ & $(6.49)$ & $(4.31)$ & $(1.01)$ & $(2.71)$ \\
metr & 0.23 & -0.25 & 0.03 & -0.18 & 0.46 & -0.31 \\
& $(1.07)$ & $(0.82)$ & $(0.22)$ & $(0.64)$ & $(1.34)$ & $(0.76)$ \\
almp & NI & 0.04 & NI & 0.03 & NI & 0.12 \\
& & $(0.55)$ & & $(0.42)$ & & $(0.51)$ \\
services & NI & 0.03 & NI & 0.03 & NI & 0.04 \\
& & $(2.96)$ & & $(1.01)$ & & $(3.71)$ \\
\hline$\widehat{R}^{2}$ & 0.09 & 0.57 & 0.01 & 0.15 & 0.13 & 0.68
\end{tabular}

Note: Based on a cross-section estimation for 14 European countries (EU 15 minus Luxembourg and plus Norway), data applies to 2005, except services where data is from 2003. All variables are measured relative to US values. The metr is the marginal effective tax rate applying to labour force participation (source: Eurostat), and almp and services measure total outlays on active labour market policy in-kind benefits (old age and family) in \% of GDP (source: www.sourceoecd.org). The regression is $\ln (p)=$ constant $+a_{1} \ln m e t r+a_{2} \ln$ almp $+a_{3} \ln$ services. Numbers in parenthesis give the numerical values of the t-statistics.

In short, taking into account the employment conditionalities of welfare arrangements the Scandinavian puzzle is accounted for. Moreover, when including both pecuniary (metr) and non-pecuniary incentives for work, the standard view that economic incentives captured by metr constitute a disincentive to labour supply and employment is recovered in the data.

\section{Employment conditional welfare policies and tax distortions}

The preceding discussion of conditionalities point to the important role both pecuniary and non-pecuniary incentives may have in affecting labour supply decisions. The labour supply considered here is labour force participation, i.e. the extensive margin of labour supply. The following presents a simple static mode ${ }^{13}$ showing how the introduction of employment conditionalities into the social safety net may have important effects on the determination of labour force participation and thus labour supply.

Consider a setting where individuals have different abilities reflected in different earnings (wages) potentials. Index individuals by $i(\in[0,1])$ and denote the potential wage for type $i$ by $w_{i}$. Wage potentials are ordered such that they are increasing in $i$. Assume that abilities are distributed across the population according to a continuous density function $f(w)$ of potential wages ${ }^{14}$. An individual type $i$

\footnotetext{
${ }^{13}$ Andersen and Svarer (2008) show in a search framework how workfare elements in an unemployment insurance scheme can shift the trade-off between insurance and incentives.

${ }^{14}$ Where $f(w)>0$ for $w \in[\underline{a}, \bar{a}]$, and $f(w)=0$ elsewhere. $\int_{0}^{\infty} f(w) d w=1$.
} 
will have utility

$$
U\left(w_{i}(1-\tau)\right)-h
$$

if working. $U\left(\right.$ ) (where $U^{\prime}>0, U^{\prime \prime}<0$ ) gives the utility from consumption equal to disposable income $w_{i}(1-\tau)$, where $\tau$ is the proportional tax rate. The disutility from work ${ }^{15}{ }^{16}$ is denoted $h$ (note that working hours are assumed exogenous).

The public sector offers a benefit scheme which provides a tax financed benefit $(b)$ with an activation requirement implying a disutility $\alpha h, \alpha \geq 0$. Hence, utility if not working is

$$
U(b)-\alpha h
$$

The parameter $\alpha$ captures the strength of the conditionality built into the benefit scheme or in short the activation requirement. In standard models $\alpha=0$ is implicitly assumed, i.e. the benefit is unconditional and the non-working has low income but enjoys more leisure.

The most straightforward interpretation of the $\alpha$ parameter is that there is a time consuming workfare element attached to receiving benefits, and the activation requirement is stated in terms of the share $\alpha$ $(\in[0,1])$ of the working hours of the employed $(h)$. It is also possible to interpret $\alpha$ as measuring the strength of the conditionality in terms of the foregone leisure due to time spend on job search or the probability of shirking on job search and the implied sanction if detected.

An alternative interpretation is that the disutility from work captures the opportunity cost of not being able to perform non-market activities (cooking, cleaning, taking care of the children, family etc. $)^{17}$ or black-market activities. Hence, if the government supplies public services which are close substitutes to non-market activities like e.g. day care facilities, it essentially works to lower the value of non-market activities (see also Ngai and Pissarides (2009)). A high $\alpha$ thus corresponds to the case where the value of having more time for home production is low, and vice versa for a high value of $\alpha$.

Finally, the parameter $\alpha$ can also be interpreted as measuring the strength of work norms (see Lindbeck (1995)), Lindbeck, Nyborg and Weibull $(1998,2003)$ ). If $\alpha$ is large, it implies that the gain in leisure from not working is small, which may reflect that it is a strong norm that one should be self-supporting, and vice versa.

\section{Reservation wage}

Consider now the labour force participation decision ${ }^{18}$. The participation constraint for individual $i$ reads

$$
U\left(w_{i}(1-t)\right)-h \geqq U(b)-\alpha h
$$

Define the critical or reservation wage $\widetilde{w}$ as

$$
U(\widetilde{w}(1-t))-d=U(b)-\alpha h
$$

\footnotetext{
${ }^{15}$ All workers are assumed to have the same disutility from work. The model can easily be generalized to allow for differences in disutility from work. This would imply that the non-working group will include both low productivity groups and high value of leisure groups.

${ }^{16}$ Since working hours are exogenous $h$ may be interpreted as the disutility of working a given number of hours, or the hours multiplied by a marginal disutility normalized to one.

${ }^{17}$ Note that Rogerson (2007) takes into account that some public schemes subsidize market work.

${ }^{18}$ It is assumed that utility out of work is always higher when receiving the benefits than when not receiving benefits; that is, the take-up rate among the non-employed is assumed to be $100 \%$.
} 
The wage $\widetilde{w}$ has the interpretation of a reservation wage determining whether there is an incentive to work or not; that is

$$
\begin{array}{ll}
w_{i} \geq \widetilde{w} & \text { individual } i \text { is working } \\
w_{i}<\widetilde{w} & \text { individual } i \text { is not working }
\end{array}
$$

i.e. there is a skill or ability effect determining who is working, and who is not. The high skilled (with high earnings ability) work and the low skilled (with low earnings ability) do not work. Note that $\widetilde{w}$ depends on the tax rate $(\tau)$, the benefit level $(b)$ and the activation requirement $(\alpha)$, i.e.

$$
\widetilde{w}(\tau, b, \alpha)
$$

where

$$
\frac{\partial \widetilde{w}}{\partial \tau}>0 ; \frac{\partial \widetilde{w}}{\partial b}>0 ; \quad \frac{\partial \widetilde{w}}{\partial \alpha}<0
$$

i.e. the reservation wage is increasing in the tax rate and the benefit level, but decreasing in the activation requirement.

Note that in the case of a linear utility function $(U(y)=y)$ we have

$$
\widetilde{w}=\frac{(1-\alpha) h}{1-m e t r}
$$

where metr $\equiv \tau+\frac{b}{\widetilde{w}}$ measures how the tax system affects the economic consequence from transiting from non-work to work, i.e. the sum of lost benefits and the tax payment, cf. section 2. Note that the metr is here measured for the marginal labour market entrant. The expression for the reservation wage in this case makes clear how the reservation wage can be lowered (and work incentives strengthened) either by strengthening pecuniary incentives to work (lowering metr) and non-pecuniary incentives (increasing $\alpha$ ).

\section{Employment}

For given policies $(\tau, b, \alpha)$ total employment is now found as

$$
L(\tau, b, \alpha) \equiv \int_{\widetilde{w}}^{\infty} f(w) d w
$$

and the number entitled to benefits is given as

$$
N(\tau, b, \alpha) \equiv \int_{0}^{\widetilde{w}} f(w) d w
$$

\section{Public sector}

The public sector offers a benefit $b$ to all out of work, and also provides public services $(g)$. All of this is financed by a proportional tax (tax rate: $\tau$ ) on labour income. The public sector budget constraint reads

$$
\tau \int_{\widetilde{w}}^{\infty} w f(w) d w=(b+\alpha c) \int_{0}^{\widetilde{w}} f(w) d w+g
$$


where $c \geq 0$ denotes the net costs of operating the activation schemes, and $g$ denotes eventual other public activities to be financed by the tax. The budget constraint can be written

$$
S \equiv \tau R-(b+\alpha c) N+g=0
$$

where $R \equiv \int_{\widetilde{w}}^{\infty} w f(w) d w$ is total (labour) income generated in the economy and thus the tax base. $S$ is the primary budget balance which in this stationary model (no debt) is required to be in balance.

Provided that the exogenous revenue requirement $(g)$ is not too high there exists a unique stable equilibrium to the model (see Appendix). If $b$ is taken as the policy instrument the tax rate follows from (2) and hence the reservation wage follows from (1) and determines the labour market outcome. To preclude that the results depend on empirically implausible effects the following only considers equilibria where $\frac{\partial f(\widetilde{w})}{\partial \widetilde{w}}>0$, i.e. the higher the reservation wage the more will at the margin be indifferent between work and non-work. This holds for any symmetric density function if the marginal entrant has a reservation wage below the mean of potential market wages.

\subsection{Labor supply and taxes}

Considering how the tax rate and the benefit level affects labour supply we have

$$
\frac{\partial L}{\partial \tau}=-\frac{\partial \widetilde{w}}{\partial \tau} f(\widetilde{w})<0 \quad ; \quad \frac{\partial L}{\partial b}=-\frac{\partial \widetilde{w}}{\partial b} f(\widetilde{w})<0
$$

i.e. both a higher tax rate and a higher benefit level make work less attractive to non-work, and therefore labour force participation decreases. This captures the standard incentive effects of taxes and benefits. However, increasing the conditionality for benefits, i.e. the work requirement (non-pecuniary incentives), we have that it increases labour force participation,

$$
\frac{\partial L}{\partial \alpha}=-f(\widetilde{w}) \frac{\partial \widetilde{w}}{\partial \alpha}>0
$$

Hence, we can conclude that a conditional transfer scheme causes labour supply to be larger than a passive transfer scheme having the same tax rate and benefit level, i.e.

$$
L(\tau, b, \alpha)>L(\tau, b, 0) \quad \text { for } \alpha>0
$$

The intuition for this result can be seen from figure 4. All individuals with a potential wage above the reservation wage $\left(w_{i} \geq \widetilde{w}\right)$ will work . Since the reservation wage in the case of an activation requirement is lower $\widetilde{w}(\alpha)<\widetilde{w}(0)$ for $\alpha>0$, it follows that the activation requirement increases employment by the shaded area in figure 4 .

\section{Figure 4: Reservation wages and employment}




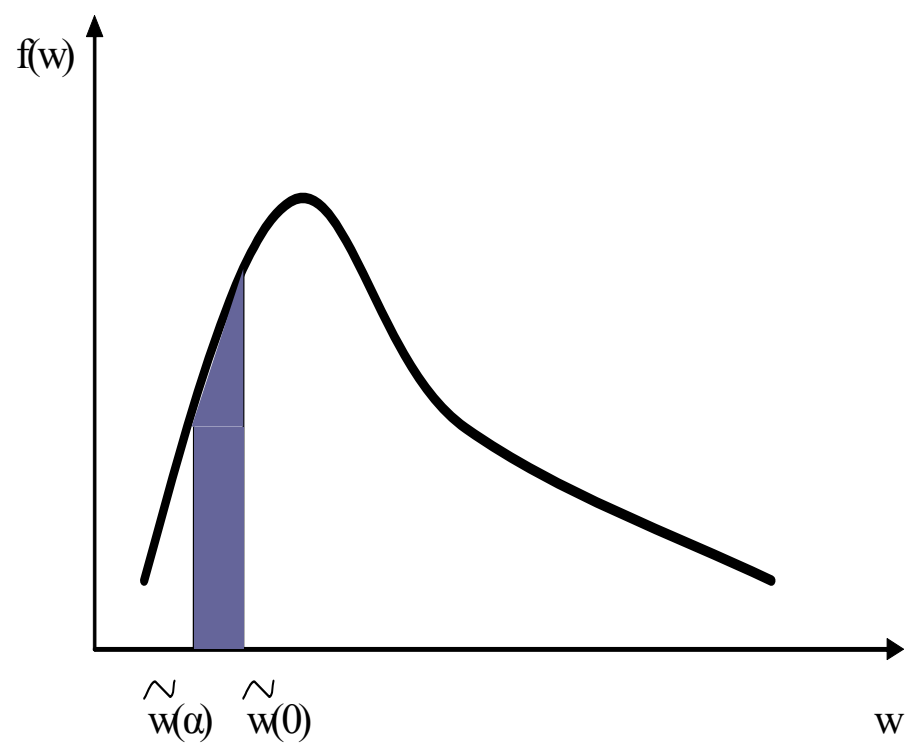

Considering next the sensitivity of total labour force participation/employment to the tax rate, we have

$$
\frac{\partial L}{\partial \tau} \frac{\tau}{L}=-\frac{\partial \widetilde{w}}{\partial \tau} \frac{\tau f(\widetilde{w})}{L}=-\frac{\tau}{1-\tau} \frac{\widetilde{w} f(\widetilde{w})}{L}<0
$$

which is negative for the standard reasons. Note that elasticity of employment wrt the tax rate can be written

$$
\frac{\partial L}{\partial \tau} \frac{\tau}{L}=-\frac{\tau}{1-\tau} \widetilde{w} \phi(\widetilde{w})
$$

where

$$
\phi(\widetilde{w}) \equiv \frac{f(\widetilde{w})}{\int_{\widetilde{w}}^{\infty} f(w) d w} \in[0,1]
$$

denotes the fraction of the employed who are working at their reservation wage $(\phi(\widetilde{w})$ is increasing in $\widetilde{w})$. The elasticity of labour supply to the tax rate depends on the tax rate itself (via $\frac{\tau}{1-\tau}$ ), the reservation wage $(\widetilde{w})$, and the fraction of the employed $(\phi(\widetilde{w}))$ who work at their reservation wage. The fact that this elasticity depends on the reservation wage implies that the effects of taxes on labour supply also depend on the conditionalities in the transfer scheme ${ }^{19}$.

The interesting question is whether activation makes labour supply more or less elastic to the tax rate (i.e. does a given tax rate distort labour force participation more or less when there is an activation requirement attached to benefit eligibility). We have that

$$
\frac{\partial}{\partial \alpha}\left[\frac{\partial L}{\partial \tau} \frac{\tau}{L}\right]=-\frac{\tau}{1-\tau}\left[\phi(\widetilde{w})+\frac{\partial \phi(\widetilde{w})}{\partial \widetilde{w}}\right] \frac{\partial \widetilde{w}}{\partial \alpha}>0
$$

\footnotetext{
${ }^{19}$ Note that (4) implies that the effects of tax reforms can be assessed from empirical estimations of how employment responds to taxes. However, empirical results are conditional on the prevailing conditionalities, and therefore empirical evidence on tax elasticities can not readily be transferred across countries with different social arrangements.
} 
Hence, on the margin a strengthening of the employment conditionality in the transfer scheme implies that labour supply becomes less elastic to the tax rate. To phrase this differently, the stronger the non-pecuinary incentives $(\alpha)$ the less important are the pecuniary incentives on the margin. Figure 5 summaries the main implication of the activation requirement for labour supply, that is, labour supply becomes larger for any tax rate (cf (3)) and less elastic to the tax rate.

Figure 5: Taxation and labour supply: the role of activation

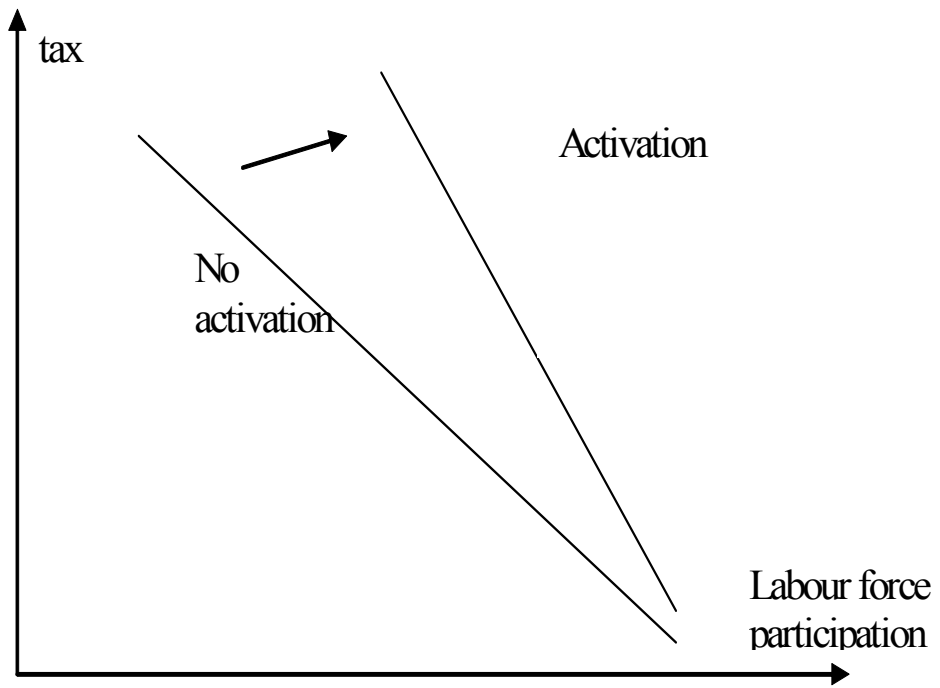

The fact that a given tax rate is less distortionary if there is an employment conditionality in the social safety net is also captured by considering the so-called marginal costs of public funds ( mcpf). In the case of linear utility the mcpf is expressed by a simple and easily interpreted expression given as (see Appendix $B$ for derivation)

$$
m c p f=\frac{1}{1+\frac{\tau R_{\tau}}{R}-\frac{\tau N_{\tau}}{N}}>1
$$

The mcpf is affected by two margins, namely, how the tax rate affects the tax base $\left(\frac{\tau R_{\tau}}{R}\right)$, and how it affects the number of transfer recipients $\left(\frac{\tau N_{\tau}}{N}\right)$. It follows straightforwardly that the mcpf is larger than one because an increase in the tax rate both reduces the income base $\left(R_{\tau}<0\right)$ and increases the number being dependent on transfers $\left(N_{\tau}>0\right)$. However, the stronger the employment conditionality (the higher $\alpha$ ) the lower the mcpf i.e.

$$
\frac{\partial m c p f}{\partial \alpha}<0
$$

The intuition is that the employment conditionality dampens the effect of taxes both on the tax base and the number of transfer recepients. In other words the disincentive effects of taxes and benefits for work are counteracted by the activation requirement.

In sum we have seen that conditionalities in the benefit scheme (activation) work to increase labour force participation for given tax rates and benefit levels (i.e. it counteracts the disincentive effects of 
both), and moreover it makes labour supply (labour force participation) more inelastic and the marginal costs of public funds lower (i.e. it becomes less costly to tax financed public activities).

\subsection{Welfare rationale for employment conditionalities?}

The preceding has worked out some basic implications of employment conditionalities in the social safety net. An important question is the welfare rationale for such conditionalities. This is a complicated question since it involves the incentive and budget effects of the policy, as well as the consequences for both employed (tax payers) and non-employed (benefit recipients).

The first point to note is that employment conditionalities reduce the cost of financing a given benefit level $b$ under the condition that ${ }^{20}$

$$
S_{\alpha}=\tau R_{\alpha}-(b+\alpha c) N_{\alpha}-c N>0 \text { for } \alpha=0
$$

i.e. there is a positive marginal effect on public net revenue of an increase in the activation requirement. Since $R_{\alpha}>0$ and $N_{\alpha}<0$ this inequality holds for $c=0$. Hence, there exists a $\bar{c}$ such that the inequality holds for $c<\bar{c}$, i.e. the costs of activation should not be too high. ${ }^{21}$

If there is a positive revenue effect of introducing the employment condition this suggests that there is room for improvement either to lower taxes or to increase the benefit level. Whether this is the case depends critically on the social welfare function which should reflect concerns about distribution, social inclusion etc. A utilitarian approach is widely taken in the economics literature to determine optimal policies. There is however several reasons to question whether this approach captures well the motivations underlying the social safety net in general, and employment conditionalities in particular. While utilitarianism can justfy some redistribution (if marginal utility of consumption differs), it is based on the ability to generate utility (redistribution goes towards those with high marginal utilities of income). The justification underlying policy debates related to labour market and socially policies usually goes wider. It is beyond the scope of this paper to go into detail on these crucial but critical issues, and it suffices to point to a few key observations. Policy debates on distribution are primarily focussing on income/consumption rather than utility and the aim to avoid working poor is essential in the Scandinavian countries. This partly reflects that income/consumption is readily measurable and interpersonally comparable, and partly views on social inclusion. The latter stresses that policies should aim at making life conditions as alike as possible irrespective of labour market status. Even though substitution between consumption and leisure can attain a given level of individual utility, it is not acceptable that some have low income (although they may enjoy much leisure) since this entails a risk of social exclusion due to lack of economic means to participate in various activities on the same level as other. It is an open question how social preferences should be formulated to capture these effects, but for the present purpose the main issues can be illustrated by taking a modified utilitarian approach which captures the essence of the above argument. This may be termed a constrained utilitarian objective

\footnotetext{
${ }^{20}$ Public sector net-revenue is $\tau R-(b+\alpha c) N$.

${ }^{21}$ Note that Besley and Coate (1992) argues that under full information the cost minimization poverty alleviating scheme never includes a workfare element. The reason in their setting is that it crowds-out hours supplied to the private labour market.
} 
function where the constraint is that the material living standard is not to fall below some minimum. In the present formulation this amount to the the transfer not to fall below some minimum level, i.e. $b \geq \underline{b}$.

Consider the optimal policy package $(\tau, b, \alpha, g)$ when the objective is to maximize

$$
\Upsilon=\int_{\widetilde{w}}^{\infty}[U((1-\tau) w)-h] f(w) d w+\int_{0}^{\widetilde{w}}[U(b)-\alpha h] f(w) d w+V(g)
$$

where $V()$ is a concave utility function giving the utility of public consumption $g$, subject to the budget constraint

$$
\tau \int_{\widetilde{w}}^{\infty} w f(w) d w=(b+\alpha c) \int_{0}^{\widetilde{w}} f(w) d w+g
$$

and the distributional constraint

$$
b \geq \underline{b}
$$

The details of this problem are worked out in the Appendix $B$.

\section{(i) No binding distributional constraint}

If the distributional constraint is non binding it follows that the optimal benefit level $b^{*}$ exceeds the minimum $\left(b^{*} \geq \underline{b}\right)$. In this case it can be shown that $\alpha^{*}=0$ i.e. that the optimal policy package does not include any employment conditionality.

One way to see the reason for this result is to start by noting that the employment conditionality affects the budget balance by

$$
S_{\alpha}=\tau R_{\alpha}-(b+\alpha c) N_{\alpha}-c N
$$

cf above. This is positive for low levels of $\alpha$ provided that the costs $c$ of running the programmes are not too high. Can an eventual budget improvement $\left(S_{\alpha}>0\right)$ be used to create a pareto improvement? Consider those receiving the transfer to find the marginal rate of substitution leaving utility unchanged we have

$$
\left.\frac{d b}{d \alpha}\right|_{\text {given utility non-working }}=\frac{h}{U_{b}}>0
$$

Hence if an employment conditionality is introduced, a higher benefit rate has to be offered if the utility of the non-working should be unchanged. The budget effect of a change in the benefit level is

$$
S_{b}=\tau R_{b}-(b+\alpha c) N_{b}-N<0
$$

i.e. an increase in the benefit level worksens the public budget. Now can the revenue generated by the employment conditionality covered the extra expenses induced by the higher benefits to leave the non-working non worse off? We have

$$
d S=S_{b} d b+S_{\alpha} d \alpha=\left[\frac{\partial S}{\partial b} \frac{h}{U_{b}()}+\frac{\partial S}{\partial \alpha}\right] d \alpha
$$

Insering from (5) and (6) and using that $\frac{\partial \widetilde{w}}{\partial \alpha}=-\frac{h}{U_{b}(b)} \frac{\partial \widetilde{w}}{\partial b}$ implies $R_{\alpha}=-\frac{h}{U_{b}(b)} R_{b}$ and $N_{\alpha}=-\frac{h}{U_{b}(b)} N_{b}$ we get

$$
d S=\frac{h}{U_{b}()}[-N-c N] d \alpha<0
$$


Hence, there is no scope for making an improvement to a policy package where $b^{*}>\underline{b}$ by including the employment conditionality. This case can also be seen a illustrating that under a classical utilitarian social welfare function there is no rationale for introducing the employment conditionality (proof is given in Appendix B).

(ii) Binding distributional constraint

In the case where the distributional constraint is binding we have $b=\underline{b}$. For the employment conditionality to be part of the optimal policy package it is required that

$$
\left.S_{\alpha}\right|_{\alpha=0}>0
$$

i.e. it is a necessary condition that employment conditionalities have a positive effect on public sector net revenue for this instrument to be used. This is however not a sufficient condition since the planner also takes into account that employment conditionalities have an opportunity cost in terms of disutility for the non-working (absent this concern the revenue effect would also be a sufficient condition). As shown in the appendix an employment conditionality $(\alpha>0)$ is part of the optimal policy package for a policy maker with a binding distributional constraint $(b=\underline{b})$ if

$$
\lambda \geq \underline{\lambda}
$$

where $\lambda$ is the Lagrange multiplier associated with the public sector budget constraint. The intuition is that the binding distributional constraint can be achieved at lower costs by including the employment conditionality, and this is welfare improving if the shadow price on public revenue is sufficiently high. In short, the employment conditionality is included when it allows the policy maker to achieve its distributional constraint at lower costs.

The results above illustrates a general point. If the policy maker wants to reduce the benefit level for incentive reasons, but is prevented from so doing due to distributional concerns (the benefit constraint is binding), it may be optimal to use employment conditionalities since this makes it possible to strengthen work incentives without jeopardizing the distributional concerns.

\section{Concluding remarks}

Recent experience shows that in some countries - notably the Scandinavian - high labour market participation and employment rates coexists with high tax levels and generous social safety nets. This may be interpreted either as a refutal of standard incentive arguments or as positioning these countries as puzzles or outliers. However, agents react both to pecuniary and non-pecuniary incentives, and therefore a generous tax financed social safety net can be made consistent with a high labour force participation (employment) rate if the disenctive effects arising from taxes and generous benefits are counteracted by other employment friendly measures.

This paper has argued that the Scandinavian experience can be accounted for when taking into account that the social safety net has strong conditionalities linking transfers to employment. Hence, the description of the social safety net as an unconstrained alternative to work is not appropriate for key welfare schemes like unemployment benefits and social assistance. Employment conditionalities serve the purpose of maintaining an employment focus also for recipients of various benefits in the social safety 
net. The interaction between pecuniary and non-pecuniary incentives is important in determining labour supply (participation), and taking this into account helps explaining both why labour supply may seem surprisingly large given taxes and benefit levels, and why high taxes are not causing larger distortions. However, this also brings out the importance of policy complementarities, and it is an important condition for maintaining a Scandinavian type welfare model that it ensures a high employment rate.

The main focus of the preceding discussion has been the extensive margin of labour supply (labour force participation). The intensive margin (working hours) is equally important. A particularly interesting question is to what extent the disincentive effects of high taxes can be countered. Employment conditionalities can more easily address the extensive than the intensive margin. Institutional arrangements like centralized wage bargaining may work to lower the effects of high taxes on the intensive margin of labour supply if e.g. working hours are decided at a centralized level. The reason is that centralized wage bargainers will internalize the public budget in its determination of wages and working hours (see Summers et al. (1993)). An interesting question for future research is whether the tendency towards more decentralized wage determination will strengthen the disincentive effects of taxes on working hours, and whether this can be countered by conditionalities in the social safety net.

\section{Appendix A: Existence of equilibrium}

The equilibrium to the model can be characterized by the following two equations:

$$
U(\widetilde{w}(1-\tau))-d=U(b)-\alpha d \quad \text { (participation) }
$$

and

$$
\int_{\widetilde{w}}^{\infty} \tau w f(w) d w=(b+\alpha c) \int_{0}^{\widetilde{w}} f(w) d w+g \quad \text { (budget) }
$$

The policy parameters $(b, \alpha, g)$ are taken as given, while the tax rate $\tau$ is endogenously determined, i.e. we have a system of two equations in the two endogenous variables $(\widetilde{w}, \tau)$. Note that $(7)$ gives a relation between the tax rate and the reservation wage, i.e. $\tau=\phi(\widetilde{w})$ for $\tau<1$. Define $\underline{\widetilde{w}}: U(\underline{\widetilde{w}})-d=U(0)-\alpha d$, i.e. the reservation wage when taxes (and hence benefits) are zero, i.e. the lowest possible minimum wage. We have

$$
\left.\frac{\partial \tau}{\partial \widetilde{w}}\right|_{\text {participation }}=\phi^{\prime}()=\frac{1-\tau}{\widetilde{w}}>0 \text { for } \widetilde{w} \geq \underline{\widetilde{w}}
$$

and

$$
\left.\frac{\partial^{2} \tau}{\partial \widetilde{w}^{2}}\right|_{\text {participation }}=\phi^{\prime \prime}()=-\frac{1-\tau}{(\widetilde{w})^{2}}<0 \text { for } \widetilde{w} \geq \underline{\widetilde{w}}
$$

The budget constraint (8) determines the tax rate as a function of the reservation wage, i.e. $\tau=\psi(\widetilde{w})$. Note that

$$
\tau \rightarrow \frac{\infty \text { for } \widetilde{w} \rightarrow \infty}{\int_{0}^{\infty} w f(w) d w} \text { for } \widetilde{w} \rightarrow \underline{\widetilde{w}}
$$


Moreover, we have from (8)

$$
\left.\frac{\partial \tau}{\partial \widetilde{w}}\right|_{\text {budget }}=\psi^{\prime}()=[b+\alpha c+\tau \widetilde{w}] \frac{f(\widetilde{w})}{\int_{\widetilde{w}}^{\infty} w f(w) d w}>0
$$

and

$$
\left.\frac{\partial^{2} \tau}{\partial \widetilde{w}^{2}}\right|_{\text {budget }}=\psi^{\prime \prime}()=\left[\widetilde{w} \frac{d \tau}{d \widetilde{w}}+\tau\right] \frac{f(\widetilde{w})}{\int_{\widetilde{w}}^{\infty} w f(w) d w}+[b+\alpha c+\tau \widetilde{w}] \frac{f_{w}(\widetilde{w}) \int_{\widetilde{w}}^{\infty} w f(w) d w+\widetilde{w}(f(\widetilde{w}))^{2}}{\left(\int_{\widetilde{w}}^{\infty} w f(w) d w\right)^{2}} \lesseqgtr 0
$$

Note that the second derivative is generally ambiguously signed, but

$$
\left.\frac{\partial^{2} \tau}{\partial \widetilde{w}^{2}}\right|_{\text {budget }}>0 \text { for } \widetilde{w}=0
$$

The equilibrium is illustrated in figure 10. For the sake of argument, the figure below is drawn for the case where it is assumed that $\left.\frac{\partial^{2} \tau}{\partial \widetilde{w}^{2}}\right|_{\text {budget }}>0$ for all $\widetilde{w}$ and $g=0$.

Figure 10: Equilibrium tax and reservation wage.

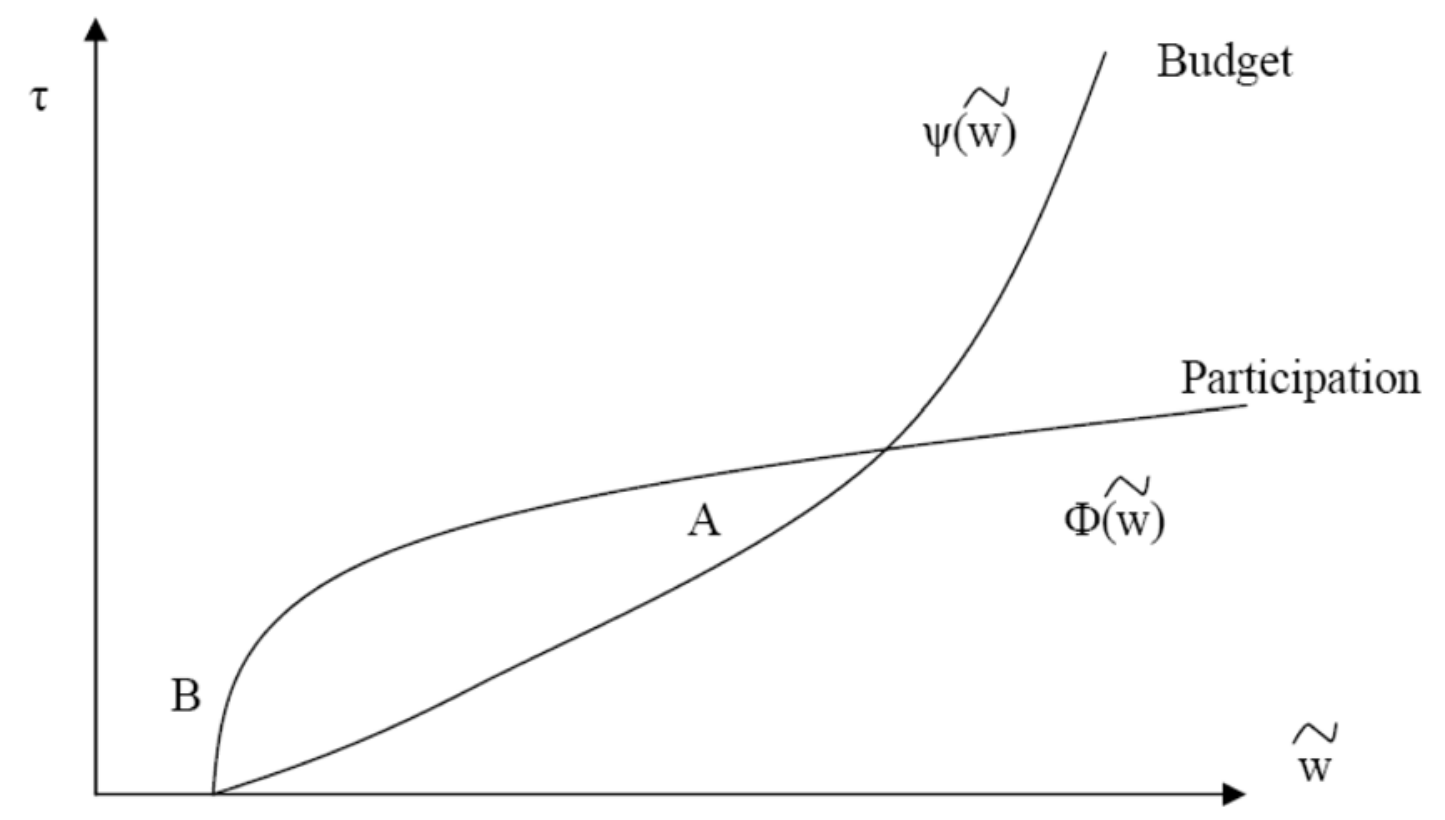

A necessary condition for an equilibrium to exist is that there exists a reservation wage $\widetilde{w}^{*}$ for which

$$
\phi\left(\widetilde{w}^{*}\right) \geq \psi\left(\widetilde{w}^{*}\right)
$$

i.e. the needed tax rate to finance the expenditures arising at the reservation wage $\widetilde{w}^{*}$ falls short of the tax rate needed to support this reservation wage. Intuitively this is only possible if the revenue 
requirement in the case of full employment is sufficiently low $(g<\underline{g})$. Note that an equilibrium always exists for $g=0$, since in this case $\phi(\underline{\widetilde{w}}) \geq \psi(\underline{\widetilde{w}})$ and

$$
\begin{array}{l|l}
\frac{\partial \tau}{\partial \widetilde{w}} & \text { participation }>0 ;\left.\frac{\partial^{2} \tau}{\partial \widetilde{w}^{2}}\right|_{\text {participation }}<0 \\
\frac{\partial \tau}{\partial \widetilde{w}} & \mid \quad \text { budget }>0 ;\left.\frac{\partial^{2} \tau}{\partial \widetilde{w}^{2}}\right|_{\text {budget }}>0
\end{array}
$$

Hence, monotonicity ensures that there exists a $\underline{g}$ such that an equilibrium exists provided that $g<\underline{g}$.

Note that there in general may be multiple equilibria (in the figure two, of which $B$ is stable), and stability requires that

$$
\left.\frac{d \tau}{d \widetilde{w}}\right|_{\text {participation }}>\left.\frac{d \tau}{d \widetilde{w}}\right|_{\text {budget }}
$$

or

$$
1>[b+\tau \widetilde{w}] \frac{\widetilde{w}}{1-\tau} \frac{f(\widetilde{w})}{\int_{\widetilde{w}}^{\infty} w f(w) d w}
$$

Note that this ensures that mcpf $>1$ (see Appendix B).

\section{Appendix B: MCPF and optimal policies}

Define the utility generated under a utilitarian criterion as

$$
\Upsilon=\int_{\widetilde{w}}^{\infty}[U((1-\tau) w)-h] f(w) d w+\int_{0}^{\widetilde{w}}[U(b)-\alpha h] f(w) d w+V(g)
$$

where $V()$ is a concave utility function giving the utility of public consumption.

The planner problem is

$$
\max _{\tau, b, g, \alpha} \Upsilon
$$

subject to the budget constraint

$$
\tau \int_{\widetilde{w}}^{\infty} w f(w) d w=(b+\alpha c) \int_{0}^{\widetilde{w}} f(w) d w+g
$$

and the distributional constraint

$$
\underline{b} \leq b
$$

The optimization problem can be written as the following Kuhn-Tucker problem

$\operatorname{Max}_{\tau, b, g, \alpha} \Gamma=\int_{\widetilde{w}}^{\infty}[U((1-\tau) w)-h] f(w) d w+\int_{0}^{\widetilde{w}}[U(b)-\alpha h] f(w) d w+V(g)+\lambda[\tau R-(b+\alpha c) N-g]+\mu(\underline{b}-b)$ 
which yields the following first order conditions

$$
\begin{gathered}
\frac{\partial \Gamma}{\partial \tau}=\int_{\widetilde{w}}^{\infty}-U_{c}() w f(w) d w+\lambda\left[R+\tau R_{\tau}-(b+\alpha c) N_{\tau}\right]=0 \\
\frac{\partial \Gamma}{\partial g}=V_{g}()-\lambda=0 \\
\frac{\partial \Gamma}{\partial \alpha}=-h N+\lambda\left[\tau R_{\alpha}-(b+\alpha c) N_{\alpha}-c N\right]=0 \\
\frac{\partial \Gamma}{\partial b}=U_{b}(b) N+\lambda\left[\tau R_{b}-(b+\alpha c) N_{b}-N\right]-\mu=0 \\
\mu\left[U_{b}(b) N+\lambda\left[\tau R_{b}-(b+\alpha c) N_{b}-N\right]\right]=0
\end{gathered}
$$

the second order conditions are assumed to be fulfilled.

\section{(I) Marginal costs of public funds}

We have from the first order condition for the tax rate (10) that

$$
-\int_{\widetilde{w}}^{\infty} w U_{c}((1-\tau) w) f(w) d w+\lambda\left[R+\tau R_{\tau}-(b+\alpha c) N_{\tau}\right]=0
$$

Hence

$$
\lambda=\frac{\int_{\widetilde{w}}^{\infty} w U_{c}((1-\tau) w) f(w) d w}{R+\tau R_{\tau}-(b+\alpha c) N_{\tau}}
$$

Note that the Lagrange multiplier $\lambda$ measures the marginal effect on utility of a marginal increase in the revenue requirement to the public sector. This is therefore a measure of the costs of raising revenue to the public sector. However, it gives a metric measured in units of utility which is hard to interpret, and therefore it is useful to transform it to a measure in monetary units. This can be done by relating the Lagrange multiplier to the marginal utility of consumption, and in the present case it is convenient to do this for the average wage, i.e. $\bar{w}=\frac{R}{L}$. Hence, we get

$$
m c p f \equiv \frac{\lambda}{\overline{U_{c}((1-\tau) \bar{w})}}=\frac{\int_{\widetilde{w}}^{\infty} w \frac{U_{c}((1-\tau) w)}{\overline{U_{c}((1-\tau) \bar{w})} f(w) d w}}{R+\tau R_{\tau}-(b+\alpha c) N_{\tau}}
$$

Assume for the sake of argument that the marginal utility (linear utility) is constant, implying that $\int_{\widetilde{w}}^{\infty} w \frac{U_{c}((1-\tau) w)}{\overline{U_{c}}((1-\tau) \bar{w})} f(w) d w=\int_{\widetilde{w}}^{\infty} w f(w) d w=R$ in which case we have ${ }^{22}$

$$
m c p f=\frac{1}{1+\frac{\tau R_{\tau}}{R}-(b+\alpha c) \frac{N_{\tau}}{R}}>1
$$

or using that the budget constraint for the public sector implies $(b+\alpha c) N=\tau R$

$$
m c p f=\frac{1}{1+\frac{\tau R_{\tau}}{R}-\frac{\tau N_{\tau}}{N}}>1
$$

\footnotetext{
${ }^{22}$ Note that stability ensures that mcpf is always larger than one, cf. Appendix A.
} 
We are interested in knowing how mcpf is affected by a change in the work requirement in the benefit scheme. To this end, it is used that

$$
\begin{aligned}
R & =\int_{\widetilde{w}}^{\infty} w f(w) d w \\
R_{\tau} & =-\frac{\partial \widetilde{w}}{\partial \tau} \widetilde{w} f(\widetilde{w})<0 \\
N_{\tau} & =\frac{\partial \widetilde{w}}{\partial \tau} f(\widetilde{w})>0
\end{aligned}
$$

it follows that mcpf can be written

$$
m c p f=\frac{1}{1-\frac{\tau \widetilde{w}+b}{R} \frac{\partial \widetilde{w}}{\partial \tau} f(\widetilde{w})}
$$

Hence, a change in the activation requirement affects the marginal costs of public funds by

$$
\frac{\partial m c p f}{\partial \alpha}=(m c p f)^{2} \frac{\partial}{\partial \alpha}\left[\frac{\tau \widetilde{w}+b}{R} \frac{\partial \widetilde{w}}{\partial \tau} f(\widetilde{w})\right]
$$

where

$$
\begin{gathered}
\frac{\partial}{\partial \alpha}\left[\frac{\tau \widetilde{w}+b}{R} \frac{\partial \widetilde{w}}{\partial \tau} f(\widetilde{w})\right]=\left[\frac{\tau \widetilde{w}}{R} \frac{\partial \widetilde{w}}{\partial a}-\frac{\tau \widetilde{w}+b}{R^{2}} \frac{\partial R}{\partial \alpha}\right] \frac{\partial \widetilde{w}}{\partial \tau} f(\widetilde{w})+\frac{\tau \widetilde{w}+b}{R}\left(\frac{\partial}{\partial \alpha} \frac{\partial \widetilde{w}}{\partial \tau}\right) f(\widetilde{w})+\frac{\tau \widetilde{w}+b}{R} \frac{\partial \widetilde{w}}{\partial \tau} \frac{\partial f(\widetilde{w})}{\partial \widetilde{w}} \frac{\partial \widetilde{w}}{\partial a} \\
\text { and } \frac{\partial \widetilde{w}}{\partial a}<0, \frac{\partial R}{\partial \alpha}>0, \frac{\partial}{\partial \alpha} \frac{\partial \widetilde{w}}{\partial \tau}=0, \text { and } \frac{\partial f(\widetilde{w})}{\partial \widetilde{w}} \frac{\partial \widetilde{w}}{\partial a}<0 . \text { Hence, } \\
\frac{\partial m c p f}{\partial \alpha}<0
\end{gathered}
$$

(II) Benefits and active labour market policies

The optimal benefit level solving (1) is determined by

$$
\begin{aligned}
& U_{b}(b)=\lambda\left[\frac{(b+\alpha c) N_{b}-\tau R_{b}+N}{N}\right] \quad \text { for } \mu=0 \text { and hence } b>\underline{b} \\
& U_{b}(\underline{b})<\lambda\left[\frac{(b+\alpha c) N_{b}-\tau R_{b}+N}{N}\right] \text { for } \mu>0 \text { and hence } b=\underline{b}
\end{aligned}
$$

Consider an initial situation where $\alpha=0$ implying that the benefit level is offered unconditionally. We want to explore whether there is a welfare case for introducing the conditionality.

The marginal welfare effect of a change in the employment conditionality is

$$
\frac{\partial \Gamma}{\partial \alpha}=-h N+\lambda\left[\tau R_{\alpha}-(b+\alpha c) N_{\alpha}-c N\right]
$$

and hence the question is whether $\left.\frac{\partial \Gamma}{\partial \alpha}\right|_{\alpha=0}>0$. We have from (13) that

$$
\lambda=\frac{U_{b}(b)+\frac{\mu}{N}}{\left[\frac{(b+\alpha c) N_{b}-\tau R_{b}+N}{N}\right]}
$$


Moreover since $\frac{\partial \widetilde{w}}{\partial \alpha}=-\frac{h}{U_{b}(b)} \frac{\partial \widetilde{w}}{\partial b}$ it follows that $R_{\alpha}=-\frac{h}{U_{b}(b)} R_{b}$ and $N_{\alpha}=-\frac{h}{U_{b}(b)} N_{b}$ and hence

$$
\tau R_{\alpha}-(b+\alpha c) N_{\alpha}-c N=\left[(b+\alpha c) N_{b}-\tau R_{b}\right] \frac{h}{U_{b}(b)}-c N
$$

Using this we have

$$
\begin{aligned}
\frac{\partial \Gamma}{\partial \alpha} & =-h N+\frac{U_{b}(b)+\frac{\mu}{N}}{\left[\frac{(b+\alpha c) N_{b}-\tau R_{b}+N}{N}\right]}\left[\left[(b+\alpha c) N_{b}-\tau R_{b}\right] \frac{h}{U_{b}(b)}-c N\right] \\
& =-h N+\frac{N U_{b}(b)-\mu}{\left[(b+\alpha c) N_{b}-\tau R_{b}+N\right]}\left[\left[(b+\alpha c) N_{b}-\tau R_{b}\right] \frac{h}{U_{b}(b)}-c N\right] \\
& =-h N+\frac{h N\left[(b+\alpha c) N_{b}-\tau R_{b}\right]-N U_{b}(b) c N}{\left[(b+\alpha c) N_{b}-\tau R_{b}+N\right]}-\mu\left[\left[(b+\alpha c) N_{b}-\tau R_{b}\right] \frac{h}{U_{b}(b)}-c N\right] \\
& \left.=\frac{-h N\left[(b+\alpha c) N_{b}-\tau R_{b}+N\right]+h N\left[(b+\alpha c) N_{b}-\tau R_{b}\right]-N U_{b}(b) c N}{\left[(b+\alpha c) N_{b}-\tau R_{b}+N\right]}-\mu\left[(b+\alpha c) N_{b}-\tau R_{b}\right] \frac{h}{U_{b}(b)}-c N\right] \\
& =\frac{-h N^{2}-N U_{b}(b) c N}{\left[(b+\alpha c) N_{b}-\tau R_{b}+N\right]}+\mu\left[\left[(b+\alpha c) N_{b}-\tau R_{b}\right] \frac{h}{U_{b}(b)}-c N\right]
\end{aligned}
$$

We now have (i) $\mu=0$

$$
\frac{\partial \Gamma}{\partial \alpha}=\frac{-h N^{2}-N U_{b}(b) c N}{\left[(b+\alpha c) N_{b}-\tau R_{b}+N\right]}<0
$$

and (ii) for $\mu>0$ we have

$$
\frac{\partial \Gamma}{\partial \alpha}=-h N+\lambda\left[\tau R_{\alpha}-(b+\alpha c) N_{\alpha}-c N\right]>0
$$

requires

$$
\lambda>\frac{h N}{\tau R_{\alpha}-(b+\alpha c) N_{\alpha}-c N}=\frac{h N}{S_{\alpha}} \equiv \underline{\lambda}
$$

which as a necessary conditon has $\left.S_{\alpha}\right|_{\alpha=0}$. This condition can also be expressed in terms of the distributional weight since

$$
\begin{aligned}
& \frac{\partial \Gamma}{\partial \alpha}>0 \text { if } \mu>\frac{h N^{2}+N U_{b}(b) c N}{\left[(b+\alpha c) N_{b}-\tau R_{b}+N\right]}\left[\left[(b+\alpha c) N_{b}-\tau R_{b}\right] \frac{h}{U_{b}(b)}-c N\right]^{-1} \equiv \underline{\mu} \\
& \frac{\partial \Gamma}{\partial \alpha} \leq 0 \text { if } \mu \geq \underline{\mu}
\end{aligned}
$$

\section{References:}

Akerlof, G.A., 1978, The Economics of "Tagging" as Applied to the Optimal Income Tax, Welfare Programs and Manpower Planning, American Economic Review, 68, 8-19.

Alesina, A., E. Glaeser and B. Sacerdote, 2005, Work and leisure in the US and Europe: Why so different?, In NBER Macroeconomics Annual, edited by Mark Gertler and Kenneth Rogoff, Cambridge Mass. MIT Press.

Algan, Y., and P. Cahuc. 2009. Civic Virtue and Labor Market Institutions. American Economic Journal: Macroeconomics, 1(1): 111-45.

Andersen, T.M., and B. Holmström, S. Honkapohja, S. Korkman, H.T. Söderström, J. Vartiainen, 2007, The Nordic Model - Embraching globalization and sharing risks. ETLA

Andersen, T.M. and M. Svarer, 2008, The Role of Workfare in Striking a balance between incentives and insurance in the labour market, CESifo working paper. 
Andersen, T.M., 2008, Workfare, redistribution and welfare, Working Paper.

Besley, T., and S. Coate, 1992, Workfare vs. Welfare: Arguments for Work Requirements in PovertyAlleviation Programs, American Economic Review, 82, 249-61.

Besley, T. and S. Coate, 1995, The design of income maintenance programs. Review of Economic Studies 62, 187-221.

Chetty, R., 2008, Is the taxable income elasticity sufficient to calculate the deadweight loss? The implications of evasion and avoidance, NBER Working Paper, 13844.

Centeno, 2005, Indicators of financial incentives to work, in European Commission (2005).

Causa, O., 2008, Explaining differences in hours worked among OECD countries: An empirical analysis, OECD Economics Department Working Paper 596.

Danish Ministry of Labour, 2007, LBK nr 1074, 07/09/2007.

Erixon, L., 2008, The Rehn-Meidner Model in Sweden: Its Rise, Challenges and Survival, Research Papers in Economics 2008:2, Department of Economics, Stockholms University.

Esping- Andersen, G., 1990, The Three Worlds of Welfare Capitalism, Polity Press.

Evers, M., R. A. de Moij, and D. J. van Vuuren, 2005, What explains the variation in estimates of labour supply elasticities? CESifo working paper 1633.

European Commission, Indicators and policies to make work pay, European Economy, Special Report no 2,2005

Gordon, R., 2006, Issues in the Comaprison of Welfare Between Europe and the United States, Working Paper.

Holzner, C., V. Meier and M. Werding, 2006, Workfare, Monitoring and Efficiency Wages, CESifo Working Paper 1749.

Kluve, J., 2006, The effectiveness of European active labour market policy, IZA Discussion paper 2018.

Lindbeck, A., 1995, Hazardous Welfare State Dynamics, American Economic Review, Papers and Proceedings, May 1995, 9-15.

Lindbeck, A, S. Nyberg and J.W. Weibull, 1999, Social Norms and Economic Incentives in the Welfare State, Quarterly Journal of Economics, 114, 1-37.

Lindbeck, A, S. Nyberg and J.W. Weibull, 2003, Social Norms and Welfare State Dynamics, Journal of the European Economic Association, 1, 533-542.

Ljungqvist, L., and T. J. Sargent, Do Taxes Explain European Employment? Indivisible Labour, Human Capital, Lotteies and Savings, CEPR Discussion paper 6196.

Marshall, T.H., 1950, Citizenship and social class, and other essays, Cambridge: Cambridge University Press.

Meghir, C., and D. Phillips, 2008, Labour Supply and Taxes, IZA Discussion paper 3405.

Robert Moffitt, R, 1983, An Economic Model of Welfare Stigma, American Economic Review, 73 (5), 1023-1035.

Ngai, R., and C. Pissarides, 2009, Welfare policy and the structural distribution of employment, working paper.

Nichols, A.L., and R. J. Zeckhauser, 1982, Targeting Transfers through restrictions on recipients, American Economic Review, 72 (2), 372-377. 
OECD, 2009, Employment Outlook, OECD, Paris

OECD, 2008, Explaining Differences in Hours Worked across OECD Countries, Economic Policy Reforms, 1,66 - 81 .

Ohanian, L., A. Raffo, and R. Rogerson, 2006, Long-term Changes in Labour Supply and Taxes: Evidence from OECD Countries, 1956-2004, NBER Working Paper 12786.

Pedersen, P.J., and N. Smith, 2002, Unemployment traps: Do financial disincentives matter?, European Sociological Review, 18, 271-88.

Prescott, E. C., 2004, Why do Americans Work So Much More Than Europeans?, Federal reseve bank of Minneaplois, Quarterly Review, 28 (1), 2-13.

Rogerson, R., 2007, Taxation and market work: Is Scandinavia an Outlier?, Economic Theory 32, 59-85.

Summers, L., J. Gruber, and R. Vegara, 1993, Taxation and the Structure of Labour Markets: The Case of Corporatism, Quarterly Journal of Economics, 385-411. 


\section{CESifo Working Paper Series}

for full list see www.cesifo-group.org/wp

(address: Poschingerstr. 5, 81679 Munich, Germany, office@cesifo.de)

3005 Jay Pil Choi and Heiko Gerlach, Global Cartels, Leniency Programs and International Antitrust Cooperation, March 2010

3006 Aneta Hryckiewicz and Oskar Kowalewski, Why do Foreign Banks Withdraw from other Countries? A Panel Data Analysis, March 2010

3007 Eric A. Hanushek and Ludger Woessmann, Sample Selectivity and the Validity of International Student Achievement Tests in Economic Research, March 2010

3008 Dennis Novy, International Trade and Monopolistic Competition without CES: Estimating Translog Gravity, April 2010

3009 Yin-Wong Cheung, Guonan Ma and Robert N. McCauley, Renminbising China's Foreign Assets, April 2010

3010 Michel Beine and Sara Salomone, Migration and Networks: Does Education Matter more than Gender?, April 2010

3011 Friedrich Schneider, Tilman Brück and Daniel Meierrieks, The Economics of Terrorism and Counter-Terrorism: A Survey (Part I), April 2010

3012 Friedrich Schneider, Tilman Brück and Daniel Meierrieks, The Economics of Terrorism and Counter-Terrorism: A Survey (Part II), April 2010

3013 Frederick van der Ploeg and Steven Poelhekke, The Pungent Smell of "Red Herrings": Subsoil Assets, Rents, Volatility and the Resource Curse, April 2010

3014 Vjollca Sadiraj, Jan Tuinstra and Frans van Winden, Identification of Voters with Interest Groups Improves the Electoral Chances of the Challenger, April 2010

3015 Guglielmo Maria Caporale, Davide Ciferri and Alessandro Girardi, Time-Varying Spot and Futures Oil Price Dynamics, April 2010

3016 Scott Alan Carson, Racial Differences in Body-Mass Indices for Men Imprisoned in $19^{\text {th }}$ Century US Prisons: A Multinomial Approach, April 2010

3017 Alessandro Fedele, Paolo M. Panteghini and Sergio Vergalli, Optimal Investment and Financial Strategies under Tax Rate Uncertainty, April 2010

3018 Laurence Jacquet, Take it or Leave it: Take-up, Optimal Transfer Programs, and Monitoring, April 2010

3019 Wilhelm Kohler and Jens Wrona, Offshoring Tasks, yet Creating Jobs?, April 2010

3020 Paul De Grauwe, Top-Down versus Bottom-Up Macroeconomics, April 2010 
3021 Karl Ove Aarbu, Demand Patterns for Treatment Insurance in Norway, April 2010

3022 Toke S. Aidt and Jayasri Dutta, Fiscal Federalism and Electoral Accountability, April 2010

3023 Bahram Pesaran and M. Hashem Pesaran, Conditional Volatility and Correlations of Weekly Returns and the VaR Analysis of 2008 Stock Market Crash, April 2010

3024 Stefan Buehler and Dennis L. Gärtner, Making Sense of Non-Binding Retail-Price Recommendations, April 2010

3025 Leonid V. Azarnert, Immigration, Fertility, and Human Capital: A Model of Economic Decline of the West, April 2010

3026 Christian Bayer and Klaus Wälde, Matching and Saving in Continuous Time: Theory and 3026-A Matching and Saving in Continuous Time: Proofs, April 2010

3027 Coen N. Teulings and Nick Zubanov, Is Economic Recovery a Myth? Robust Estimation of Impulse Responses, April 2010

3028 Clara Graziano and Annalisa Luporini, Optimal Delegation when the Large Shareholder has Multiple Tasks, April 2010

3029 Erik Snowberg and Justin Wolfers, Explaining the Favorite-Longshot Bias: Is it RiskLove or Misperceptions?, April 2010

3030 Doina Radulescu, The Effects of a Bonus Tax on Manager Compensation and Welfare, April 2010

3031 Helmut Lütkepohl, Forecasting Nonlinear Aggregates and Aggregates with Timevarying Weights, April 2010

3032 Silvia Rocha-Akis and Ronnie Schöb, Welfare Policy in the Presence of Unionised Labour and Internationally Mobile Firms, April 2010

3033 Steven Brakman, Robert Inklaar and Charles van Marrewijk, Structural Change in OECD Comparative Advantage, April 2010

3034 Dirk Schindler and Guttorm Schjelderup, Multinationals, Minority Ownership and TaxEfficient Financing Structures, April 2010

3035 Christian Lessmann and Gunther Markwardt, Decentralization and Foreign Aid Effectiveness: Do Aid Modality and Federal Design Matter in Poverty Alleviation?, April 2010

3036 Eva Deuchert and Conny Wunsch, Evaluating Nationwide Health Interventions when Standard Before-After Doesn't Work: Malawi's ITN Distribution Program, April 2010

3037 Eric A. Hanushek and Ludger Woessmann, The Economics of International Differences in Educational Achievement, April 2010 
3038 Frederick van der Ploeg, Aggressive Oil Extraction and Precautionary Saving: Coping with Volatility, April 2010

3039 Ainura Uzagalieva, Evžen Kočenda and Antonio Menezes, Technological Imitation and Innovation in New European Union Markets, April 2010

3040 Nicolas Sauter, Jan Walliser and Joachim Winter, Tax Incentives, Bequest Motives, and the Demand for Life Insurance: Evidence from two Natural Experiments in Germany, April 2010

3041 Matthias Wrede, Multinational Capital Structure and Tax Competition, April 2010

3042 Burkhard Heer and Alfred Maussner, A Note on the Computation of the Equity Premium and the Market Value of Firm Equity, April 2010

3043 Kristiina Huttunen, Jukka Pirttilä and Roope Uusitalo, The Employment Effects of Low-Wage Subsidies, May 2010

3044 Matthias Kalkuhl and Ottmar Edenhofer, Prices vs. Quantities and the Intertemporal Dynamics of the Climate Rent, May 2010

3045 Bruno S. Frey and Lasse Steiner, Pay as you Go: A New Proposal for Museum Pricing, May 2010

3046 Henning Bohn and Charles Stuart, Population under a Cap on Greenhouse Gas Emissions, May 2010

3047 Balázs Égert and Rafal Kierzenkowski, Exports and Property Prices in France: Are they Connected?, May 2010

3048 Thomas Eichner and Thorsten Upmann, Tax-Competition with Involuntary Unemployment, May 2010

3049 Taiji Furusawa, Kazumi Hori and Ian Wooton, A Race beyond the Bottom: The Nature of Bidding for a Firm, May 2010

3050 Xavier Vives, Competition and Stability in Banking, May 2010

3051 Thomas Aronsson and Erkki Koskela, Redistributive Income Taxation under Outsourcing and Foreign Direct Investment, May 2010

3052 Michael Melvin and Duncan Shand, Active Currency Investing and Performance Benchmarks, May 2010

3053 Sören Blomquist and Laurent Simula, Marginal Deadweight Loss when the Income Tax is Nonlinear, May 2010

3054 Lukas Menkhoff, Carol L. Osler and Maik Schmeling, Limit-Order Submission Strategies under Asymmetric Information, May 2010 
3055 M. Hashem Pesaran and Alexander Chudik, Econometric Analysis of High Dimensional VARs Featuring a Dominant Unit, May 2010

3056 Rabah Arezki and Frederick van der Ploeg, Do Natural Resources Depress Income Per Capita?, May 2010

3057 Joseph Plasmans and Ruslan Lukach, The Patterns of Inter-firm and Inter-industry Knowledge Flows in the Netherlands, May 2010

3058 Jenny E. Ligthart and Sebastian E. V. Werner, Has the Euro Affected the Choice of Invoicing Currency?, May 2010

3059 Håkan Selin, Marginal Tax Rates and Tax-Favoured Pension Savings of the SelfEmployed - Evidence from Sweden, May 2010

3060 Richard Cornes, Roger Hartley and Yuji Tamura, A New Approach to Solving Production-Appropriation Games with Many Heterogeneous Players, May 2010

3061 Ronald MacDonald and Flávio Vieira, A Panel Data Investigation of Real Exchange Rate Misalignment and Growth, May 2010

3062 Thomas Eichner and Rüdiger Pethig, Efficient Management of Insecure Fossil Fuel Imports through Taxing(!) Domestic Green Energy?, May 2010

3063 Vít Bubák, Evžen Kočenda and Filip Žikeš, Volatility Transmission in Emerging European Foreign Exchange Markets, May 2010

3064 Leonid V. Azarnert, Après nous le Déluge: Fertility and the Intensity of Struggle against Immigration, May 2010

3065 William E. Becker, William H. Greene and John J. Siegfried, Do Undergraduate Majors or Ph.D. Students Affect Faculty Size?, May 2010

3066 Johannes Becker, Strategic Trade Policy through the Tax System, May 2010

3067 Omer Biran and Françoise Forges, Core-stable Rings in Auctions with Independent Private Values, May 2010

3068 Torben M. Andersen, Why do Scandinavians Work?, May 2010 